\title{
Influence of Tetra Alkyl Ammonium Cation and Temperature on Molecular Interactions Involves in Binary Liquid Mixtures of Dioxane and DMF at Various Temperatures
}

\author{
${ }^{1}$ Indu Saxena, ${ }^{2}$ Vijay Kumar, ${ }^{3}$ Rikkam Devi \\ 1,2, 3 Department of Chemistry, University of Lucknow, Lucknow (up) 226007, India
}

\begin{abstract}
Ultrasonic velocity $(u)$, density $(\rho)$, viscosity $(\eta)$ and related acoustical parameters such as adiabatic compressibility $(\beta)$, free energy $(\Delta G)$, internal pressure $\left(\pi_{i}\right)$, relaxation time $(\tau)$ and acoustic impedance $(z)$ have been computed using standard relation for tetra alkyl ammonium cation $\left(E t_{4} N^{+}, \mathrm{Pr}_{4} N^{+}, B u_{4} N^{+}\right.$, and $\left.P e n_{4} N^{+}\right)$in binary liquid mixtures of 1, 4 - Dioxane and $N, N$-Dimethyl Formamide was prepared of 0.14M on different percentage compositions over the temperature range from $303.15 \mathrm{~K}$ to $323.15 \mathrm{~K}$ with the interval of $10 \mathrm{~K}$ under room pressure to investigate inter - ionic interactions. The densities were measured by Magnetic Float Densitometer. Transport properties provide a deep and meaningful insight of various interactions taking place. It has been observed that the influence of small as well as large alkyl chain length of tetra alkyl ammonium cations $\left(R_{4} N^{+}\right)$, in terms of shape and ionic size with the DMF solvent in the presence of Dioxane, is helpful in investigating the molecular interactions, molecular rearrangement, molecular association etc.
\end{abstract}

Keywords: Ultrasonic velocity, Density, Viscosity, Acoustical parameters, 1, 4-Dioxane, N, N-Dimethyl Formamide, $R_{4} N I$ salts and molecular interactions.

\section{Introduction}

The analysis of the reliable thermo-dynamical parameter and its deviation from the ideality of the properties of liquid mixtures provide some important information about the molecular organization and their interactions that is essential for the industrial design and attaining acceptable chemical theories. In many chemical engineering areas such as process design, oil fraction characterization, and others, accurate estimation of thermodynamic, optical, and ultrasonic properties as a function of composition and temperature is particularly important [1]. In recent years, ultrasonic techniques has become a powerful tool in providing information regarding the molecular interactions of liquid mixtures owing to its ability of characterizing physiochemical behavior of the medium [2-10]. The experimental values of acoustical parameters allow us to establish a new predictive structural interaction that tells about the structural information of the liquid mixtures at various temperatures that are desirable for many chemical industries in a fast reliable and economical way [11-15]. Therefore, a deep knowledge of thermo-physical properties of binary ILs mixtures containing cation $\left(\mathrm{Et}_{4} \mathrm{~N}^{+}\right.$, $\mathrm{Pr}_{4} \mathrm{~N}^{+}, \mathrm{Bu}_{4} \mathrm{~N}^{+}$, and $\mathrm{Pen}_{4} \mathrm{~N}^{+}$) of mixed organic solvent are required for many practical applications have essentially required for scientific community [16].

The physiochemical properties such as density $(\rho)$, viscosity $(\eta)$ and ultrasonic velocity $(u)$ of binary liquid mixtures of 1,4 - Dioxane and $\mathrm{N}, \mathrm{N}$ - Dimethyl Formamide containing $\mathrm{R}_{4} \mathrm{~N}^{+}$cation, are used to identify the behavior and its nature of structure, making or breaking effect through molecular interactions. Thermodynamic functions have also been used as a qualitative and quantitative inspect to predict the extent of complex formation, molecular interactions and molecular association in these types of liquid mixtures [17]. Many researchers have studied molecular interactions and structural properties of solution containing tetra alkyl ammonium salts in aqueous as well as non-aqueous binary solvent mixtures. Frank explained the high activity coefficient on the basis of his hypothesis according to which the structure of water is enforced around the $\mathrm{R}_{4} \mathrm{~N}^{+}$ions on account of water-hating influence of large alkyl chain [18]. This result confirms that formation of cavities inside the enhanced water structure and $\mathrm{R}_{4} \mathrm{~N}^{+}$ions are accommodated in the cavities so formed [19]. RN Pathak et al. reported various observations by taking aqueous and non-aqueous binary solvent mixture, adding $\mathrm{R}_{4} \mathrm{NI}$ salts and showing the validity of Frank's hypothesis for salts solutions [20]. Their observations were confirmed that such solute - solvent hating effect is still there and structure of any of the binary solvents is affected by the ion - solvent interactions.

An adequate knowledge of the thermo-physical properties of ammonium-based molecular solvents are essentially required to clarify the nature of molecular interactions between these solvents, as well as to design new chemical and technological processes [21]. 1, 4 - Dioxane is found in two forms; one is the boat form (polar) and second is the chair form (non-polar). These confirmations depend on the energy of the molecular system. Dioxane is known as an inert solvent having low dielectric constant $(\epsilon) 2.2$ as compared to DMF (36.71). DMF is a stable compound with a strong $\mathrm{e}^{-}$pair donating and accepting ability and is widely used in setting such as solvent reactivity relationship. 


\section{Experimental And Theoretical Methods}

Ultrasonic velocity (u) are measured for the binary liquid mixtures of DMF and Dioxane, in the presence of ammonium salt using a single crystal ultrasonic interferometer at $2 \mathrm{MHz}$ frequency (Model-83S) supplied by Mittal enterprises, New Delhi, that has an accuracy of $0.4 \mathrm{~m} / \mathrm{Sec}$ at $25^{\circ} \mathrm{C}$. The temperature was kept constant, by constant temperature water bath with an accuracy of $\pm 0.1 \mathrm{~K}$. The densities and viscosities of selected binary system were determined at different temperatures by magnetic float densitometer [22] and Ostwald's viscometer respectively and calculated by using eq. $1 \& 2$.

$$
\text { Density }(\rho)=(\mathrm{W}+\mathrm{w}+\mathrm{f} \times \mathrm{I}) /\left(\mathrm{V}+\mathrm{w} / \rho_{\mathrm{pt}}\right)
$$

The terms involved in this equation have their usual meanings. The data of solution mixtures, i.e., weight, $\mathrm{w}$ used, current, I, passing in the circuit, $\rho_{\mathrm{pt}}$ density of pt and $\mathrm{V}$, volume of float.

$$
\eta_{\mathrm{s}} / \eta_{\mathrm{w}}=\rho_{\mathrm{s}} / \rho_{\mathrm{w}} \times \mathrm{t}_{\mathrm{s}} / \mathrm{t}_{\mathrm{w}}
$$

Where, $\eta_{w}, \rho_{w}$ and $t_{w}$ are the viscosity, density and time flow of water respectively and $\eta_{\mathrm{s}}, \rho_{\mathrm{s}}$ and $t_{\mathrm{s}}$ are the viscosity, density and time flow of unknown liquid mixture respectively.

The tetra alkyl ammonium iodide salts, $\mathrm{Et}_{4} \mathrm{NI}, \mathrm{Pr}_{4} \mathrm{NI}, \mathrm{Bu}_{4} \mathrm{NI}$ and $\mathrm{Pen}_{4} \mathrm{NI}$ which were used in present investigation were purified by the method of Conway et al [26]. 1, 4 - Dioxane and N, N - Dimethyl Formamide (DMF) of Qualigen's Glaxo grade, after drying on freshly ignited quicklime, was purified by distilling under reduced pressure. The middle fractions of the successive distillate were redistilled under reduced pressure till the electrical conductance of the final product was of the order of $10^{-7} \mathrm{ohm}^{-1} \mathrm{~cm}^{-1}$. The purified samples were stored in dark coloured bottles. 1, 4 - Dioxane was used to prepare 0, 20, 40, 60, 80 and 100\% (v/v) solvent mixtures with N, N- Dimethyl Formamide of Fluka purum grade. We have been measured the values of dialectic constant $(\epsilon)$ for different \% compositions of Dioxane and DMF with the help of BI-870 dielectric constant meter (absolute accuracy to $\pm 2 \%$ ).

\section{Result And Discussion}

Virtually, the thermo-physical properties of liquid mixtures with $\mathrm{R}_{4} \mathrm{~N}^{+}$ions mainly depend on the nature, structure of ions and the alkyl chain length of the cation. It was observed that, for a given concentration and temperature, ultrasonic velocity (u), decreases with increasing the \% composition of Dioxane in DMF as shown in Table 2, 3, 4 \& 5. Such decrease in velocity gives an indication of existence of molecular association between the components of the mixture [23-25]. Again increasing trend of adiabatic compressibility $\left(\beta_{\mathrm{ad}}\right)$ is observed with increasing \% composition of Dioxane in DMF. This increasing trend of $\beta_{\text {ad }}$ values can be explained on the basis of the effect of dielectric constant $(€)$ of the solvent media. It is known that electrostatic forces of attraction, $\mathrm{F}$, between the ions, is inversely proportional to dielectric constant of solvent medium (i.e. $\mathrm{F}$ $\alpha 1 / €)$, The decrease in the value of dielectric constant of the solvent medium results in strong electrostatic forces of attraction between the ions and hence ion - ion interactions become stronger and stronger as there is a gradual decrease of dielectric constant of the medium.

In the present study, the gradual decrease of dielectric constant of medium was done by increasing the Dioxane content in the DMF as given in Table 1. Hence the increase values of $\beta_{\text {ad }}$ are obtained as shown in Fig. $1 \& 2$. This happens because there is a significant interaction between ions and solvent molecules suggesting a structure promoting behaviour of the added both compositions. This may also indicate that decrease in the number of free ions showing the occurrence of increase of ionic association due to strong electro-static force of attraction [27]. Here adiabatic compressibility $\left(\beta_{\mathrm{ad}}\right)$ and sound velocity (u) shows positive and negative deviation respectively. According to Eyring and Kincaid, the sound velocity decreases if the molecular association increases which are reflected in the present investigation [21].

Table 1: Measured values of dielectric constant $(\epsilon)$ by BI-870 Dielectric Constant Meter (absolute accuracy to $\pm 2 \%$ ) for various compositions of 1, 4 - Dioxane and N, N-Dimethyl Formamide.

\begin{tabular}{|c|c|c|c|}
\hline \multirow{2}{*}{ S.N. } & \multicolumn{2}{|c|}{ \% Compositions of Solvents } & \multirow{2}{*}{$\begin{array}{c}\text { Dielectric Constants } \\
(\boldsymbol{\epsilon})\end{array}$} \\
\cline { 2 - 3 } & Dioxane & DMF & $\mathbf{3 6 . 7 1}$ \\
\hline 1. & $\mathbf{0}$ & $\mathbf{1 0 0}$ & $\mathbf{2 9 . 5 0}$ \\
\hline 2. & $\mathbf{2 0}$ & $\mathbf{8 0}$ & $\mathbf{2 3 . 0 0}$ \\
\hline 3. & 40 & $\mathbf{6 0}$ & $\mathbf{1 5 . 0 0}$ \\
\hline 4. & $\mathbf{6 0}$ & $\mathbf{4 0}$ & $\mathbf{0 9 . 0 0}$ \\
\hline 5. & $\mathbf{8 0}$ & $\mathbf{2 0}$ & $\mathbf{0 2 . 1 0}$ \\
\hline 6. & $\mathbf{1 0 0}$ & $\mathbf{0}$ & \\
\hline
\end{tabular}


Influence of Tetra Alkyl Ammonium Cation and Temperature on Molecular Interactions Involves in

Table 2: Summary of experimental data: Density $(\rho)$, Ultrasonic velocity $(u)$, Viscosity $(\eta)$ and the derived acoustical parameters of 1, 4-Dioxane $+\mathrm{N}, \mathrm{N}$-Dimethyl Formamide $+\mathrm{Et}_{4} \mathrm{NI}$ salt mixtures at different temperatures.

\begin{tabular}{|c|c|c|c|c|c|c|c|c|c|}
\hline \multicolumn{2}{|c|}{$\begin{array}{c}\% \text { Compositions of } \\
\text { solvents }\end{array}$} & \multirow[t]{2}{*}{$\underset{\left(\mathrm{g} / \mathrm{cm}^{3}\right)}{\rho}$} & \multirow[t]{2}{*}{$\begin{array}{l}\eta \times 10^{3} \\
\left(\mathrm{Nsm}^{-2}\right)\end{array}$} & \multirow[t]{2}{*}{$\underset{\left(\mathbf{m s}^{-1}\right)}{\mathbf{u}}$} & \multirow[t]{2}{*}{$\begin{array}{c}\beta \times 10^{-10} \\
\left(\mathrm{Kg}^{-1} \mathrm{~ms}^{2}\right)\end{array}$} & \multirow[t]{2}{*}{$\begin{array}{l}\Delta \mathbf{G} \times 10^{-21} \\
\left(\text { gjmol }^{-1}\right)\end{array}$} & \multirow[t]{2}{*}{$\begin{array}{c}\pi_{\mathrm{i}} \\
(\mathbf{a t m})\end{array}$} & \multirow[t]{2}{*}{$\begin{array}{c}\tau \times 10^{-10} \\
(s)\end{array}$} & \multirow[t]{2}{*}{$\begin{array}{c}\mathrm{Z} \times 10^{3} \\
\left(\mathrm{Kgm}^{-2} \mathrm{~s}^{-1}\right)\end{array}$} \\
\hline Dioxane & DMF & & & & & & & & \\
\hline \multicolumn{10}{|c|}{ At 303.15K } \\
\hline $\mathbf{0}$ & 100 & 0.9420 & 1.3310 & 1399 & 5.354 & 0.9285 & 14103.62 & 9.501 & 133.49 \\
\hline 20 & 80 & 0.9584 & 1.3425 & 1375 & 5.543 & 0.8498 & 14188.67 & 9.921 & 132.34 \\
\hline 40 & 60 & 0.9750 & 1.3625 & 1352 & 5.593 & 0.8067 & 16645.59 & 10.16 & 132.23 \\
\hline 60 & 40 & 0.9937 & 1.4125 & 1327 & 5.681 & 0.7206 & 15148.03 & 10.699 & 133.39 \\
\hline 80 & 20 & 1.0125 & 1.4575 & 1305 & 5.728 & 0.6408 & 15245.33 & 11.13 & 133.06 \\
\hline 100 & $\mathbf{0}$ & 1.0266 & 1.5752 & 1290 & 5.804 & 0.4759 & 15853.11 & 12.19 & 132.55 \\
\hline \multicolumn{10}{|c|}{ At 313.15K } \\
\hline $\mathbf{0}$ & 100 & 0.9379 & 0.6520 & 1391 & 5.510 & 2.1835 & 10109.36 & 4.790 & 130.46 \\
\hline 20 & 80 & 0.9532 & 0.6625 & 1365 & 5.630 & 2.1132 & 10267.23 & 4.973 & 130.11 \\
\hline 40 & 60 & 0.9725 & 0.6751 & 1337 & 5.752 & 2.0378 & 12124.86 & 5.177 & 130.02 \\
\hline 60 & 40 & 0.9860 & 0.6923 & 1315 & 5.865 & 1.9538 & 11718.90 & 5.414 & 130.65 \\
\hline 80 & 20 & 1.0015 & 0.7115 & 1298 & 5.926 & 1.8834 & 10842.63 & 5.621 & 129.99 \\
\hline 100 & $\mathbf{0}$ & 1.0164 & 0.7250 & 1267 & 6.128 & 1.7848 & 11069.26 & 5.924 & 128.77 \\
\hline \multicolumn{10}{|c|}{ At $323.15 \mathrm{~K}$} \\
\hline $\mathbf{0}$ & 100 & 0.9354 & 0.6102 & 1340 & 5.953 & 2.1711 & 10264.38 & 4.843 & 125.34 \\
\hline 20 & 80 & 0.9475 & 0.6375 & 1315 & 6.103 & 2.0382 & 10546.91 & 5.187 & 124.59 \\
\hline 40 & 60 & 0.9650 & 0.6715 & 1282 & 6.305 & 1.8743 & 12678.10 & 5.645 & 123.71 \\
\hline 60 & 40 & 0.9875 & 0.6954 & 1255 & 6.429 & 1.7688 & 12419.28 & 5.961 & 123.93 \\
\hline 80 & 20 & 1.0025 & 0.7376 & 1227 & 6.625 & 1.5967 & 11747.88 & 6.515 & 123.00 \\
\hline 100 & $\mathbf{0}$ & 1.0295 & 0.7624 & 1205 & 6.689 & 1.5141 & 12119.17 & 6.799 & 122.88 \\
\hline
\end{tabular}

Table 3: Summary of experimental data: Density ( $\rho)$, Ultrasonic velocity (u), Viscosity $(\eta)$ and the derived acoustical parameters of 1, 4-Dioxane $+\mathrm{N}, \mathrm{N}$-Dimethyl Formamide $+\mathrm{Pr}_{4} \mathrm{NI}$ salt mixtures at different

\begin{tabular}{|c|c|c|c|c|c|c|c|c|c|}
\hline \multicolumn{2}{|c|}{$\begin{array}{c}\% \text { Compositions of } \\
\text { solvents }\end{array}$} & \multirow[t]{2}{*}{$\underset{\left(\mathrm{g} / \mathrm{cm}^{3}\right)}{\rho}$} & \multirow[t]{2}{*}{$\begin{array}{l}\eta \times 10^{3} \\
\left(\mathrm{Nsm}^{-2}\right)\end{array}$} & \multirow[t]{2}{*}{$\underset{\left(\mathbf{m s}^{-1}\right)}{\mathbf{u}}$} & \multirow[t]{2}{*}{$\begin{array}{c}\boldsymbol{\beta} \times \mathbf{1 0}^{-10} \\
\left(\mathrm{Kg}^{-1} \mathrm{~ms}^{2}\right)\end{array}$} & \multirow[t]{2}{*}{$\begin{array}{l}\Delta \mathbf{G} \times \mathbf{1 0}^{-21} \\
\left(\text { gjmol }^{-1}\right)\end{array}$} & \multirow[t]{2}{*}{$\begin{array}{c}\pi_{\mathrm{i}} \\
(\mathbf{a t m})\end{array}$} & \multirow[t]{2}{*}{$\begin{array}{c}\tau \times 10^{-10} \\
(s)\end{array}$} & \multirow[t]{2}{*}{ 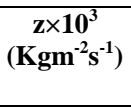 } \\
\hline Dioxane & DMF & & & & & & & & \\
\hline \multicolumn{10}{|c|}{ At 303.15K } \\
\hline $\mathbf{0}$ & 100 & 0.9498 & 1.5328 & 1366 & 5.632 & 0.5801 & 10232.61 & 11.510 & 129.74 \\
\hline 20 & 80 & 0.9650 & 1.5875 & 1356 & 5.685 & 0.4993 & 10468.11 & 12.033 & 131.41 \\
\hline 40 & 60 & 0.9807 & 1.6075 & 1346 & 5.701 & 0.4714 & 10591.87 & 12.219 & 132.40 \\
\hline 60 & 40 & 1.0100 & 1.6325 & 1343 & 5.752 & 0.4272 & 10810.65 & 12.520 & 134.00 \\
\hline 80 & 20 & 1.0125 & 1.6687 & 1322 & 5.811 & 0.3688 & 10923.67 & 12.929 & 135.21 \\
\hline 100 & $\mathbf{0}$ & 1.0324 & 1.6993 & 1311 & 5.906 & 0.3064 & 11103.51 & 13.381 & 135.34 \\
\hline \multicolumn{10}{|c|}{ At 313.15K } \\
\hline $\mathbf{0}$ & 100 & 0.9387 & 0.6643 & 1360 & 5.489 & 2.0654 & 6919.58 & 5.101 & 127.66 \\
\hline 20 & 80 & 0.9554 & 0.6801 & 1345 & 5.520 & 2.0128 & 7059.57 & 5.246 & 128.40 \\
\hline 40 & 60 & 0.9750 & 0.6862 & 1337 & 5.737 & 1.9949 & 7144.85 & 5.296 & 129.23 \\
\hline 60 & 40 & 0.9875 & 0.6950 & 1305 & 5.924 & 2.8066 & 7281.64 & 5.489 & 129.84 \\
\hline 80 & 20 & 1.005 & 0.7052 & 1296 & 5.997 & 1.8774 & 7375.00 & 5.639 & 130.15 \\
\hline 100 & 0 & 1.0169 & 0.7128 & 1282 & 6.205 & 1.7941 & $\begin{array}{l}7376.60 \\
\end{array}$ & 5.895 & 130.26 \\
\hline \multicolumn{10}{|c|}{ At 323.15K } \\
\hline 0 & 100 & 0.9228 & 0.5627 & 1333 & 5.349 & 2.2813 & $\begin{array}{l}6563.00 \\
\end{array}$ & 4.575 & 123.00 \\
\hline 20 & 80 & 0.9375 & 0.5825 & 1307 & 5.542 & 2.1687 & 6753.76 & 4.849 & 123.67 \\
\hline 40 & 60 & 0.9525 & 0.6153 & 1299 & 5.633 & 2.0385 & 6973.82 & 5.186 & 124.33 \\
\hline 60 & 40 & 0.9795 & 0.6357 & 1281 & 5.759 & 1.9509 & 7214.34 & 5.426 & 124.82 \\
\hline 80 & 20 & 1.0015 & 0.6625 & 1267 & 5.798 & 1.8420 & 7443.22 & 5.740 & 125.75 \\
\hline 100 & 0 & 1.0162 & 0.6934 & 1224 & 5.807 & 1.7331 & $\begin{array}{l}7754.79 \\
\end{array}$ & 6.072 & 125.38 \\
\hline
\end{tabular}

Table 4: Summary of experimental data: Density $(\rho)$, Ultrasonic velocity $(u)$, Viscosity $(\eta)$ and the derived acoustical parameters of 1, 4-Dioxane $+\mathrm{N}, \mathrm{N}$-Dimethyl Formamide $+\mathrm{Bu}_{4} \mathrm{NI}$ salt mixtures at different temperatures.

\begin{tabular}{|c|c|c|c|c|c|c|c|c|c|}
\hline \multicolumn{2}{|c|}{$\begin{array}{c}\% \text { Compositions of } \\
\text { solvents }\end{array}$} & \multirow[t]{2}{*}{$\begin{array}{c}\rho \\
\left(\mathrm{g} / \mathrm{cm}^{3}\right)\end{array}$} & \multirow[t]{2}{*}{$\begin{array}{l}\boldsymbol{\eta} \times \mathbf{1 0}^{3} \\
\left(\mathrm{Nsm}^{-2}\right)\end{array}$} & \multirow[t]{2}{*}{$\underset{\left(\mathbf{m s}^{-1}\right)}{\mathbf{u}}$} & \multirow[t]{2}{*}{$\begin{array}{c}\beta \times 10^{-10} \\
\left(\mathrm{Kg}^{-1} \mathrm{~ms}^{2}\right)\end{array}$} & \multirow[t]{2}{*}{$\begin{array}{l}\Delta \mathbf{G} \times 10^{-21} \\
\left(\mathrm{gjmol}^{-1}\right)\end{array}$} & \multirow[t]{2}{*}{$\begin{array}{c}\pi_{\mathrm{i}} \\
(\mathbf{a t m})\end{array}$} & \multirow[t]{2}{*}{$\begin{array}{c}\tau \times 10^{-10} \\
(s)\end{array}$} & \multirow[t]{2}{*}{ 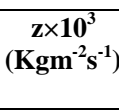 } \\
\hline Dioxane & DMF & & & & & & & & \\
\hline \multicolumn{10}{|c|}{ At 303.15K } \\
\hline
\end{tabular}


Influence of Tetra Alkyl Ammonium Cation and Temperature on Molecular Interactions Involves in

\begin{tabular}{|c|c|c|c|c|c|c|c|c|c|}
\hline $\mathbf{0}$ & 100 & 0.9536 & 1.4483 & 1405 & 5.312 & 0.7892 & 8394.74 & 10.258 & 133.98 \\
\hline 20 & 80 & 0.9657 & 1.4825 & 1393 & 5.336 & 0.7388 & 8534.15 & 10.547 & 134.52 \\
\hline 40 & 60 & 0.9824 & 1.5250 & 1365 & 5.463 & 0.6446 & 8775.38 & 11.108 & 134.97 \\
\hline 60 & 40 & 0.9990 & 1.5625 & 1344 & 5.541 & 0.5747 & 8982.08 & 11.544 & 134.26 \\
\hline 80 & 20 & 1.0323 & 1.6025 & 1323 & 5.587 & 0.5138 & 9298.63 & 11.937 & 136.57 \\
\hline 100 & $\mathbf{0}$ & 1.0396 & 1.6369 & 1315 & 6.106 & 0.3184 & 9398.32 & 13.326 & 136.70 \\
\hline \multicolumn{10}{|c|}{ At 313.15K } \\
\hline $\mathbf{0}$ & 100 & 0.9395 & 0.5989 & 1388 & 5.520 & 2.3396 & 5555.04 & 4.408 & 130.40 \\
\hline 20 & 80 & 0.9553 & 0.6275 & 1370 & 5.577 & 2.2328 & 5741.85 & 4.666 & 130.87 \\
\hline 40 & 60 & 0.9750 & 0.6575 & 1330 & 5.798 & 2.0722 & 5999.73 & 5.083 & 130.95 \\
\hline 60 & 40 & 0.9875 & 0.6925 & 1304 & 5.955 & 1.9249 & 6223.54 & 5.498 & 134.20 \\
\hline 80 & 20 & 1.0025 & 0.7250 & 1287 & 6.022 & 1.8178 & 6423.92 & 5.821 & 134.72 \\
\hline 100 & $\mathbf{0}$ & 1.0177 & 0.7512 & 1276 & 6.135 & 1.7161 & 6582.52 & 6.145 & 135.15 \\
\hline \multicolumn{10}{|c|}{ At 323.15K } \\
\hline 0 & 100 & 0.9302 & 0.5672 & 1328 & 6.095 & 2.2670 & $\begin{array}{l}5665.68 \\
\end{array}$ & 4.609 & 123.53 \\
\hline 20 & 80 & 0.9502 & 0.5868 & 1313 & 6.104 & 2.1985 & 5832.12 & 4.775 & 124.76 \\
\hline 40 & 60 & 0.9625 & 0.6025 & 1283 & 6.311 & 2.0828 & 5982.70 & 5.069 & 124.95 \\
\hline 60 & 40 & 0.9725 & 0.6371 & 1264 & 6.436 & 1.9364 & 6192.68 & 5.467 & 125.24 \\
\hline 80 & 20 & 1.0015 & 0.6532 & 1240 & 6.493 & 1.8709 & 6406.22 & 5.655 & 125.89 \\
\hline 100 & $\mathbf{0}$ & 1.0173 & 0.6921 & 1218 & 6.626 & 1.7214 & 6671.82 & 6.109 & 126.35 \\
\hline
\end{tabular}

Table 5: Summary of experimental data: Density ( $\rho)$, Ultrasonic velocity (u), Viscosity $(\eta)$ and the derived acoustical parameters of 1, 4-Dioxane $+\mathrm{N}$, N-Dimethyl Formamide $+\mathrm{Pen}_{4} \mathrm{NI}$ salt mixtures at different temperatures.

\begin{tabular}{|c|c|c|c|c|c|c|c|c|c|}
\hline \multicolumn{2}{|c|}{$\begin{array}{c}\% \text { Compositions of } \\
\text { solvents }\end{array}$} & \multirow[t]{2}{*}{$\begin{array}{c}\rho \\
\left(\mathrm{g} / \mathrm{cm}^{3}\right)\end{array}$} & \multirow[t]{2}{*}{$\begin{array}{l}\boldsymbol{\eta} \times \mathbf{1 0}^{3} \\
\left(\mathrm{Nsm}^{-2}\right)\end{array}$} & \multirow[t]{2}{*}{$\underset{\left(\mathrm{ms}^{-1}\right)}{\mathbf{u}}$} & \multirow[t]{2}{*}{$\begin{array}{c}\boldsymbol{\beta} \times 10^{-10} \\
\left(\mathrm{Kg}^{-1} \mathrm{~ms}^{2}\right)\end{array}$} & \multirow[t]{2}{*}{$\begin{array}{l}\Delta \mathbf{G} \times \mathbf{1 0}^{-21} \\
\left(\mathrm{gjmol}^{-1}\right)\end{array}$} & \multirow[t]{2}{*}{$\begin{array}{c}\pi_{\mathrm{i}} \\
(\mathbf{a t m})\end{array}$} & \multirow[t]{2}{*}{$\begin{array}{c}\tau \times 10^{-10} \\
(\mathrm{~s})\end{array}$} & \multirow[t]{2}{*}{ 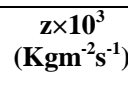 } \\
\hline Dioxane & DMF & & & & & & & & \\
\hline \multicolumn{10}{|c|}{ At 303.15K } \\
\hline 0 & 100 & 0.9484 & 1.4284 & 1396 & 5.370 & 0.7947 & 7249.55 & 10.227 & 132.39 \\
\hline 20 & 80 & 0.9665 & 1.4750 & 1388 & 5.410 & 0.7230 & 7430.13 & 10.639 & 133.15 \\
\hline 40 & 60 & 0.9825 & 1.5020 & 1368 & 5.538 & 0.6476 & 8786.40 & 11.090 & 133.78 \\
\hline 60 & 40 & 1.0025 & 1.5625 & 1354 & 5.640 & 0.5425 & 7824.25 & 11.750 & 134.06 \\
\hline 80 & 20 & 1.0250 & 1.6013 & 1341 & 5.693 & 0.4810 & 8022.26 & 12.155 & 134.68 \\
\hline 100 & 0 & 1.0348 & 1.6471 & 1311 & 5.712 & 0.4237 & 8224.55 & 12.544 & 135.66 \\
\hline \multicolumn{10}{|c|}{ At 313.15K } \\
\hline 0 & 100 & 0.9373 & 0.5748 & 1379 & 5.610 & 2.3866 & 4742.40 & 4.299 & 129.25 \\
\hline 20 & 80 & 0.9551 & 0.6273 & 1366 & 5.651 & 2.2089 & 5005.80 & 4.726 & 130.46 \\
\hline 40 & 60 & 0.9750 & 0.6625 & 1342 & 5.694 & 2.0920 & 5225.39 & 5.029 & 130.84 \\
\hline 60 & 40 & 0.9925 & 0.7052 & 1320 & 5.782 & 1.9462 & 5462.74 & 5.436 & 131.01 \\
\hline 80 & 20 & 1.0050 & 0.7425 & 1294 & 5.942 & 1.7982 & 5669.60 & 5.882 & 131.77 \\
\hline 100 & $\mathbf{0}$ & 1.0198 & 0.7931 & 1266 & 6.118 & 1.6197 & 5941.21 & 6.469 & 132.13 \\
\hline \multicolumn{10}{|c|}{ At 323.15K } \\
\hline $\mathbf{0}$ & 100 & 0.9283 & $\mathbf{0 . 5 2 1 7}$ & 1347 & 5.385 & 2.6716 & 4687.20 & 3.740 & 125.04 \\
\hline 20 & 80 & 0.9402 & 0.5625 & 1321 & 5.499 & 2.4824 & 4922.40 & 4.124 & 125.40 \\
\hline 40 & 60 & 0.9625 & 0.5957 & 1289 & 5.937 & 2.2230 & 5172.63 & 4.715 & 125.89 \\
\hline 60 & 40 & 0.9875 & 0.6551 & 1257 & 6.095 & 1.9877 & 5549.11 & 5.324 & 126.35 \\
\hline 80 & 20 & 1.0030 & 0.6732 & 1235 & 6.435 & 1.8299 & 5694.96 & 5.776 & 126.94 \\
\hline 100 & $\mathbf{0}$ & 1.0112 & 0.7013 & 1219 & 6.655 & 1.6859 & 5842.30 & 6.222 & 127.45 \\
\hline
\end{tabular}

However as the \% composition of Dioxane increases in the DMF content, $\beta_{\text {ad }}$ value increases in a slightly nonlinear manner as shown in Fig. 2 and departure from their linearity increases on increasing the temperature of the system, the value of adiabatic compressibility $\left(\beta_{\text {ad }}\right)$ is greater for $\operatorname{Pr}_{4} \mathrm{NI}$ salt solution at $303.15 \mathrm{~K}$ while it is found higher for $\mathrm{Pen}_{4} \mathrm{NI}$ at $323.15 \mathrm{~K}$. Such type of variations in the above curve of the $\beta_{\mathrm{ad}}$ depends on the size of the solute and solvent molecules and types of molecular interactions such as dipole dipole, dipole - induced dipole etc. as well as molecular rearrangement between the components of the binary liquid mixtures as shown in Scheme 2. This is in agreement with the observations made by Syal et al. and Kalyanasundaram for alkali bromides in DMSO + Dioxane and poly methylacrylate (PMMA) in DMF mixture respectively at different temperatures [28-30]. Therefore, the present investigation prove that the constituent of component present in different shapes and size, involve specific molecular interactions between them, where as $\mathrm{Bu}_{4} \mathrm{~N}^{+}$and $\mathrm{Pen}_{4} \mathrm{~N}^{+}$ions present larger in size than ions $\left(\mathrm{Et}_{4} \mathrm{~N}^{+}, \mathrm{Pr}_{4} \mathrm{~N}^{+}\right)$have lower value of adiabatic compressibility $\left(\beta_{\text {ad }}\right)$. Also, this can be understood on the basis of accommodation of solvent molecules inside the void space of large bulky group as $\mathrm{Bu}_{4} \mathrm{~N}^{+}$and $\mathrm{Pen}_{4} \mathrm{~N}^{+}$ions as compared to $\mathrm{Et}_{4} \mathrm{~N}^{+}$and $\mathrm{Pr}_{4} \mathrm{~N}^{+}$ions [18], causes very weak repulsive forces between them and thus the system becomes compact like structure. So, solvent 
molecules could not be able to penetrate in to the vacant space of the $\mathrm{Et}_{4} \mathrm{~N}^{+}$and $\operatorname{Pr}_{4} \mathrm{~N}^{+}$ions, causes expansion of the system and having higher value of adiabatic compressibility as shown in Scheme 3.

Free energy $(\Delta \mathrm{G})$ decreases with increasing \% composition of Dioxane in DMF for all the system. At $303.15 \mathrm{~K}, \mathrm{Et}_{4} \mathrm{NI}$ salt solution has larger value of free energy while $\mathrm{Pen}_{4} \mathrm{NI}$ salt solution has greater value of free energy at $323.15 \mathrm{~K}$ as shown in Fig. $3 \& 4$. At all temperatures, $\operatorname{Pr}_{4} \mathrm{~N}^{+}$shows lower activity towards $\Delta \mathrm{G}$ when $\%$ composition of DMF is higher while at $323.15 \mathrm{~K}, \mathrm{Pen}_{4} \mathrm{~N}^{+}$has higher activity at higher \% composition of Dioxane. At $323.15 \mathrm{~K}, \mathrm{Et}_{4} \mathrm{~N}^{+}$and $\mathrm{Pr}_{4} \mathrm{~N}^{+}$have lower and higher activity of $\Delta \mathrm{G}$ respectively as shown in Fig. 4. This trend of positive and negative deviations confirms that the properties of ILs mixture are affected by molecular rearrangement, molecular interactions and size of the ions at various temperatures.

The decrease in free energy suggests shorter time for rearrangement of molecules. This is attributed to hydrogen bonding charge transfer between molecules of the solution mixture. As the mixture consists of polar and non-polar liquids, in addition to dipole-dipole interactions there is a dipole-induced dipole interaction, which leads to decreasing values of $\Delta \mathrm{G}$ after increasing the $\%$ composition of Dioxane in DMF. This observation confirms that the formation of hydrogen bonding is strong with DMF and very weak with Dioxane in the binary liquid mixtures. Dioxane present in chair conformation, which is non-polar molecule shown in Scheme 3.

The internal pressure $\left(\pi_{\mathrm{i}}\right)$ slowly increases on increasing the $\%$ of Dioxane in DMF liquid but decreases on increasing the temperatures for all the system. The values of internal pressure are higher for Et $\mathrm{t}_{4} \mathrm{NI}$ salt solution at $303.15 \mathrm{~K}$ as well as at $323.15 \mathrm{~K}$ and also showed trends of linearity at all temperatures as shown in Fig. $5 \& 6$. The internal pressure may give information regarding the nature and strength of force existing between the molecules. On increasing 20 to $80 \%$ of Dioxane in DMF, the increase in the values of internal pressure indicates the presence of some specific molecular interactions between unlike molecules in the components. The structure of liquid is determined by strong attractive forces in the liquid with the relatively weak repulsive forces providing the internal pressure which leads to repulsive liquid molecules together [31]. On increasing the temperature from $303.15 \mathrm{~K}$ to $323.15 \mathrm{~K}$ of the system, the internal pressure is more sensitive to attractive forces.

The relaxation time $(\tau)$ slowly increases with increasing 20 to $80 \%$ Dioxane in DMF content for all the system. The values of relaxation time are larger for $\operatorname{Pr}_{4} \mathrm{NI}$ and lowered for $\mathrm{Et}_{4} \mathrm{NI}$ and also showed trends of linearity at $303.15 \mathrm{~K}$ as shown in Fig. 7. But deviations increases on increasing the temperature of the system and the value of $\tau$ is higher for $\mathrm{Et}_{4} \mathrm{NI}$ and lowered for $\mathrm{Pen}_{4} \mathrm{NI}$ at $323.15 \mathrm{~K}$ as shown in Fig. 8 and $303.15 \mathrm{~K}, \mathrm{Pr}_{4} \mathrm{NI}$ has higher activity towards relaxation time. The dispersion of ultrasonic velocity in the system should contain information about the characteristics time $(\tau)$ of the relaxation process that causes dispersion [32].

The relaxation time $(\tau)$ decreases with increase in the size of $\mathrm{R}_{4} \mathrm{~N}^{+}$ions from $\mathrm{Et}_{4} \mathrm{~N}^{+}$ion to $\operatorname{Pen}_{4} \mathrm{~N}^{+}$ion. Also, the value of $\tau$ decreases with rise in temperature is shown in Fig. $7 \& 8$. This trend of non - linearity curve of $\tau$ indicates that there are weak as a well as strong ionic interaction involves between the components of the binary liquid mixtures. The increase in acoustic impedance (z) values on increasing 20 to $80 \%$ of Dioxane in DMF content can be attributed to the effective solute-solvent interactions.

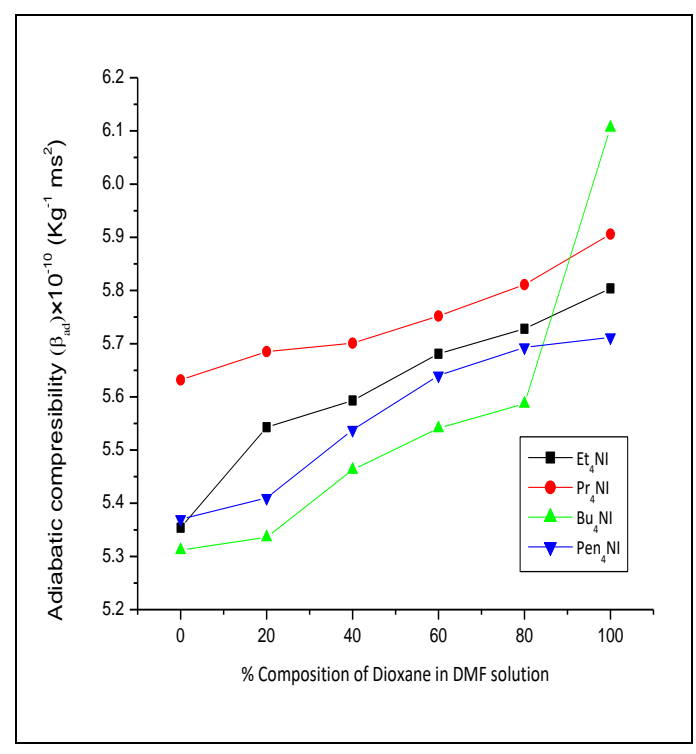

Fig. 1: Adiabatic compressibility $\left(\beta_{\mathrm{ad}}\right)$ vs \% compositions of binary liquid mixture with different salts at $303.15 \mathrm{~K}$. 


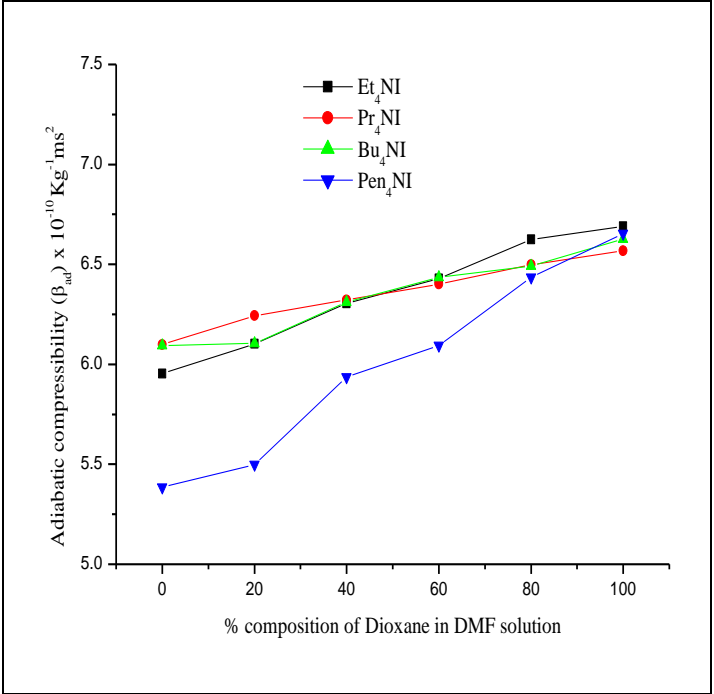

Fig. 2: Adiabatic compressibility $\left(\beta_{\mathrm{ad}}\right)$ vs \% compositions of binary liquid mixture with different salts at $323.15 \mathrm{~K}$.

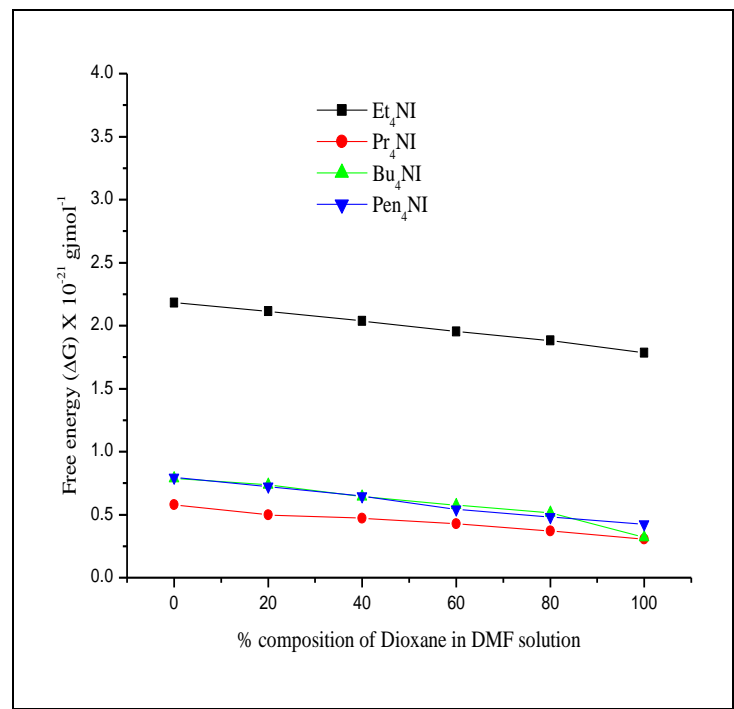

Fig. 3: Free energy $(\Delta \mathrm{G})$ vs \% compositions of binary liquid mixture with different salts at $303.15 \mathrm{~K}$.

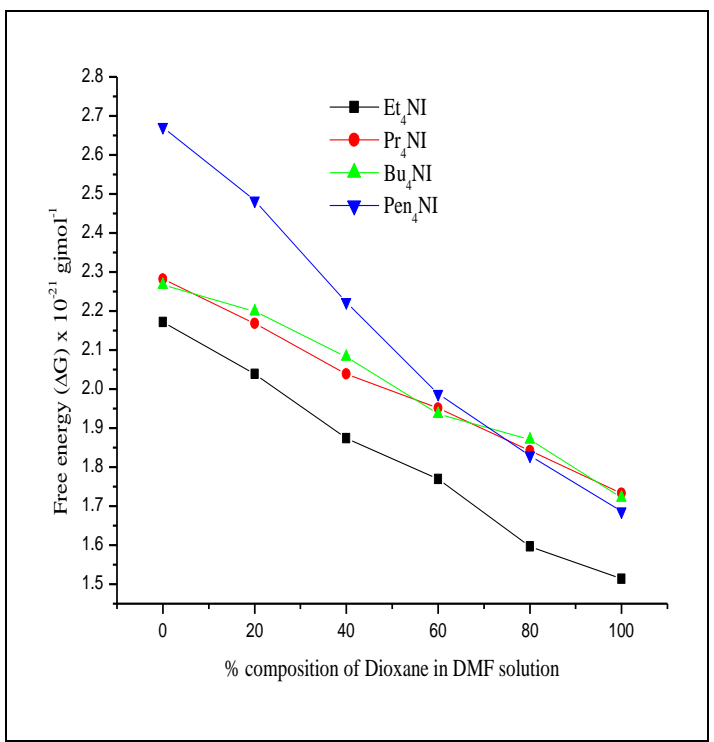

Fig. 4: Free energy $(\Delta \mathrm{G})$ vs \% compositions of binary liquid mixture with different salts at $323.15 \mathrm{~K}$. 


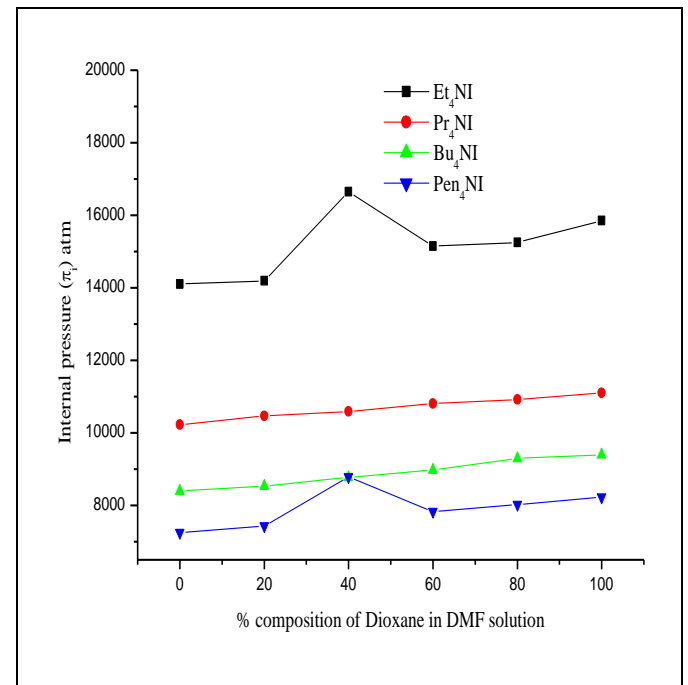

Fig. 5: Internal pressure $\left(\pi_{\mathrm{i}}\right)$ vs \% compositions of binary liquid mixture with different salts at $303.15 \mathrm{~K}$.

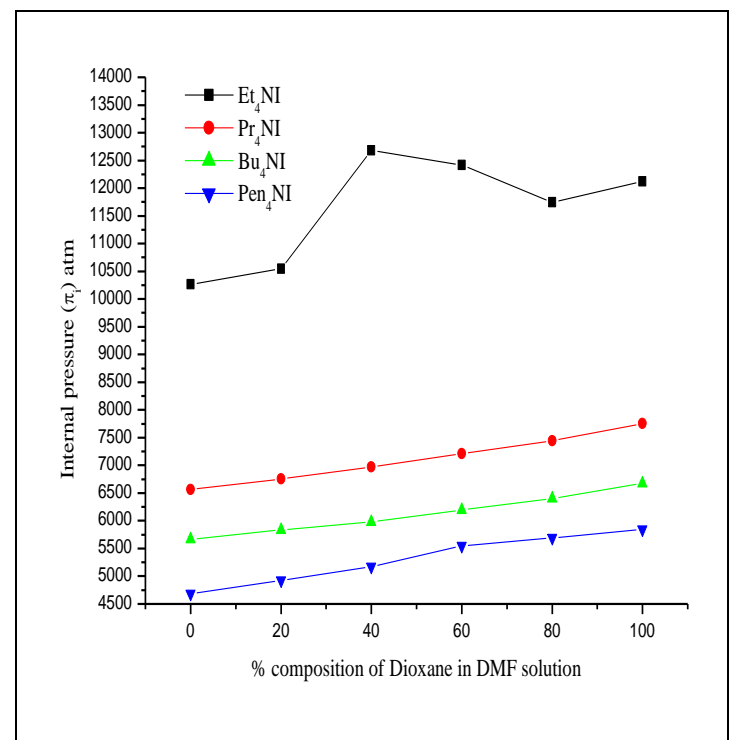

Fig. 6: Internal pressure $\left(\pi_{\mathrm{i}}\right)$ vs $\%$ compositions binary liquid mixture with different salts at $323.15 \mathrm{~K}$.

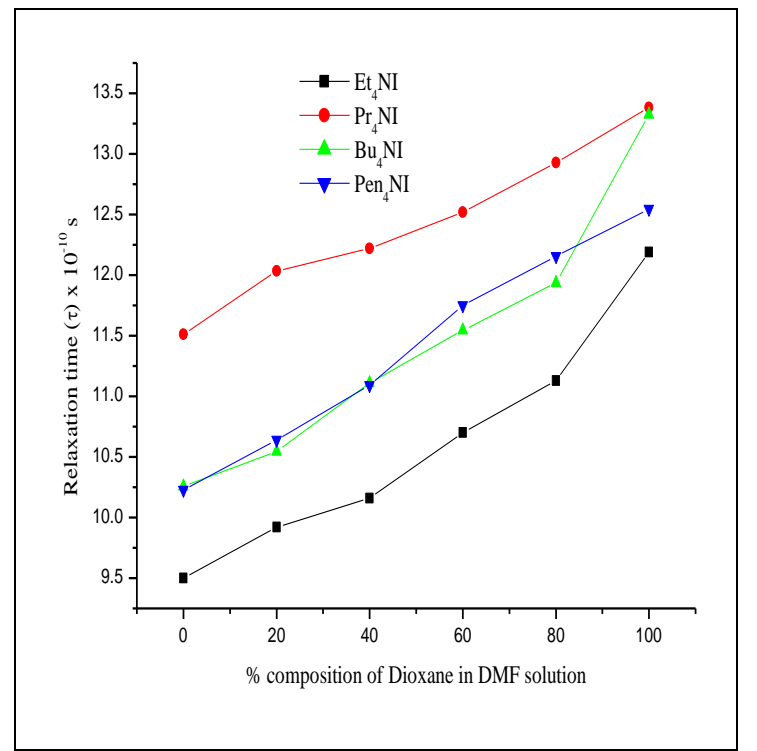

Fig. 7: Relaxation time $(\tau)$ vs \% compositions of binary liquid mixture with different salts at $303.15 \mathrm{~K}$. 


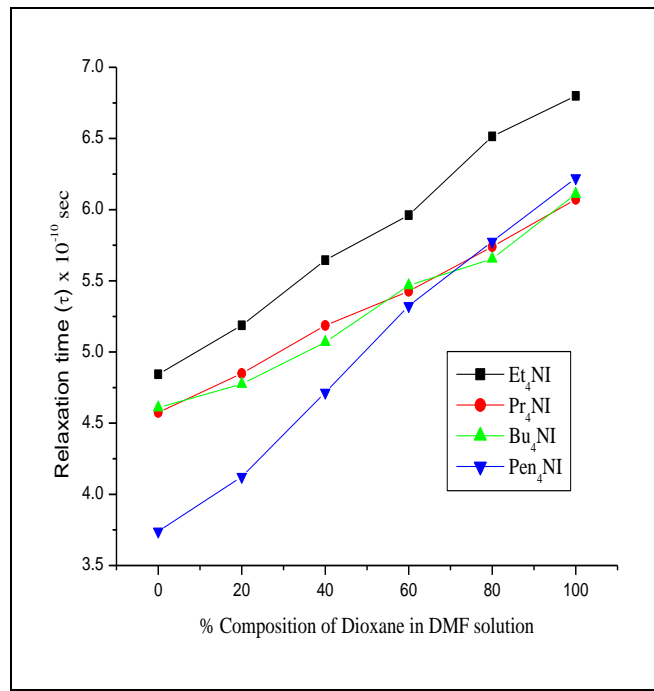

Fig. 8: Relaxation time ( $\tau$ ) vs \% compositions of binary liquid mixture with different salts at $323.15 \mathrm{~K}$.

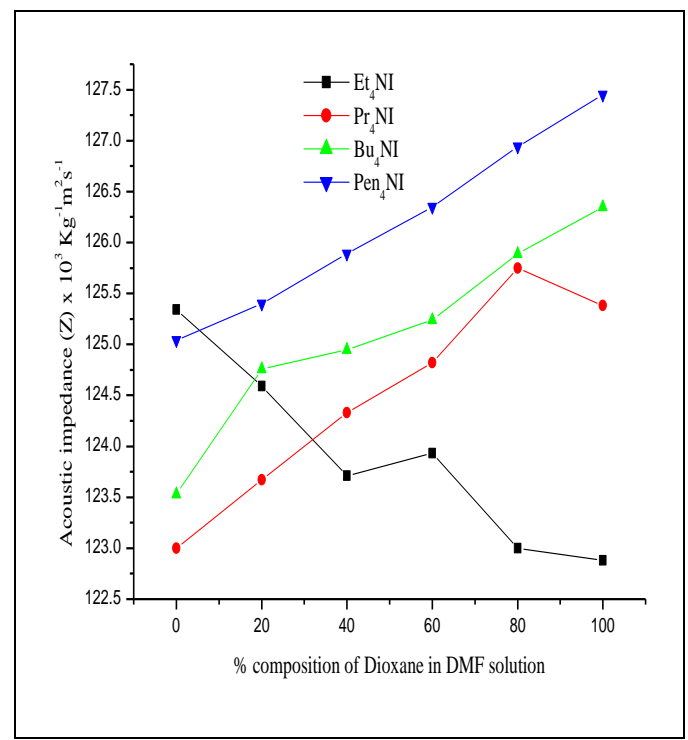

Fig. 9: Acoustic impedance (Z) vs \% compositions binary liquid mixture with different salts at 303.15K.

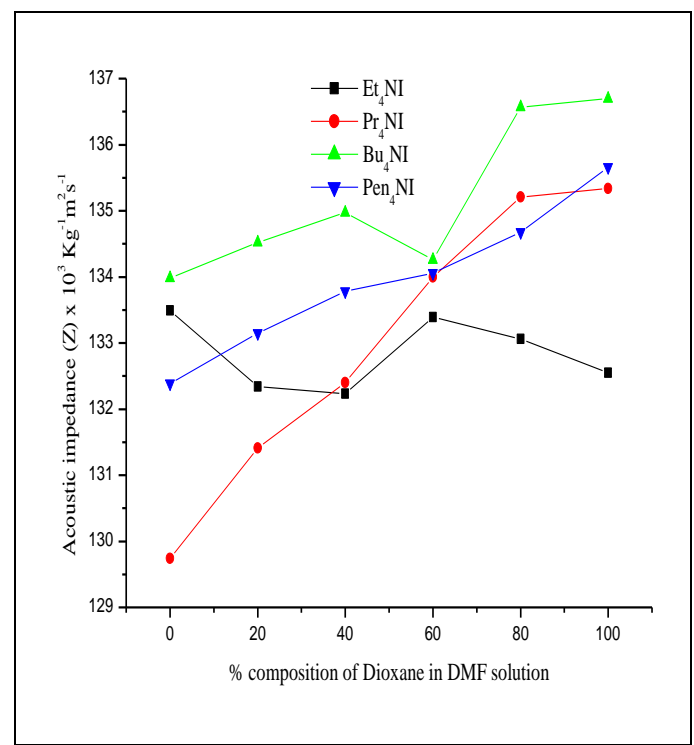

Fig. 10: Acoustic impedance (Z) vs \% compositions of binary liquid mixture with different salts at 323.15K. 
A similar type of behaviour except $\mathrm{Et}_{4} \mathrm{~N}^{+}$cation has been obtained for various salts studied in different systems. All the solution mixtures showed departure from the trends of linearity at $303.15 \mathrm{~K}$ but it showed linear trends at $323.15 \mathrm{~K}$ are shown in Fig. $9 \& 10$. The acoustic impedance is a measure of the resistance offered by the liquid medium, i.e., the bulk modulus of elasticity, which depends on the structural changes of the solution [33]. The change in the values of $\mathrm{z}$ can be understood on the basis of ionic size and bigger size alkyl chains which provide large number of cavities inside the alkyl chains than those available in smaller size alkyl chains. The molecules of solvent mixtures are accommodated inside these void spaces of alkyl chain of $\mathrm{R}_{4} \mathrm{NI}$.

\section{Conclusion}

The work performed intends to map the thermo-physical behavior of two important families of DMF and Dioxane based on ammonium families (i.e. $\mathrm{Et}_{4} \mathrm{~N}^{+}, \mathrm{Pr}_{4} \mathrm{~N}^{+}, \mathrm{Bu}_{4} \mathrm{~N}^{+}, \mathrm{Pen}_{4} \mathrm{~N}^{+}$). All of them have the same cations of different size and having small as well as large void space, which showed specific behavior with binary liquid mixture at different temperatures. Obviously, fascinating results are obtained for structure and temperature dependent properties of unique kinds of DMF with Dioxane solvent and showes the nature of liquid with small void space to large void space with increasing alkyl chain length of $\mathrm{R}_{4} \mathrm{NI}$ salt. The obtained theoretical and experimental result data; are helpful in understanding mixing effect and other existing molecular interactions during the ions transporting process. Furthermore; some specific type of molecular interactions of with Dioxane are obtained, when Dioxane is converted from boat to chair confirmation. Dioxane present within the large void space of alky chain in the chair form while boats form present away from cation. At every time DMF molecule present in polar form and formed hydrogen bonding with the molecules of Dioxane and very few molecules are able to penetrate into the void space of higher alky chain length because it created stronger dipole interactions with the alkyl chain as compared to Dioxane liquid mixture.

Scheme 1: 3D - molecular structure of Tetraethyl ammonium iodide $\left(\mathrm{Et}_{4} \mathrm{NI}\right)$, Tetraproylammonium iodide $\left(\mathrm{Pr}_{4} \mathrm{NI}\right)$, Tetrabutylammonium iodide $\left(\mathrm{Bu}_{4} \mathrm{NI}\right)$ and Tetrapentyl ammonium iodide $\left(\mathrm{Pen}_{4} \mathrm{NI}\right)$ salts molecules.

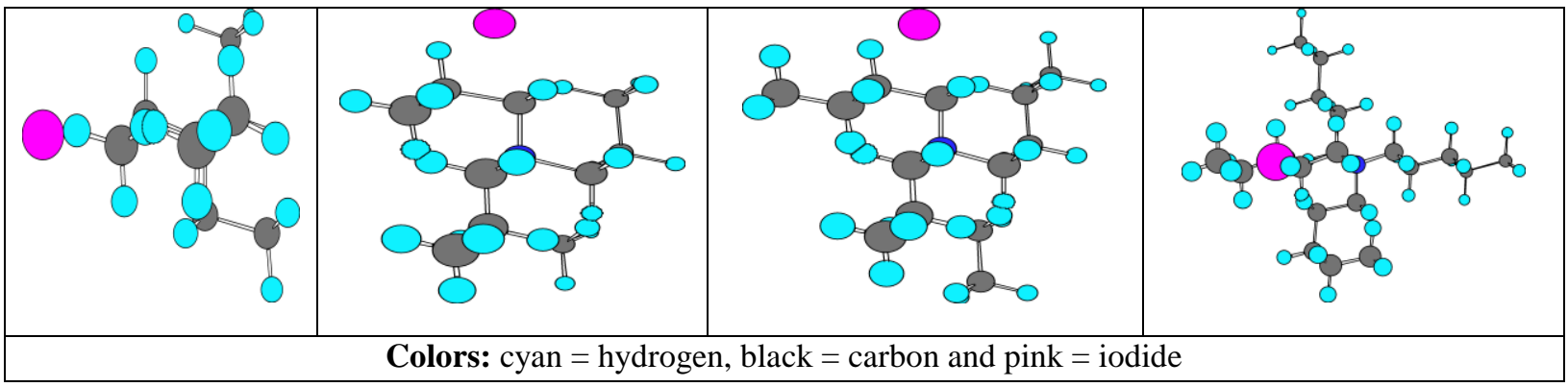

Scheme 2: Showing hydrogen bonding, Types of molecular interactions occurred between the components of binary liquid mixtures.

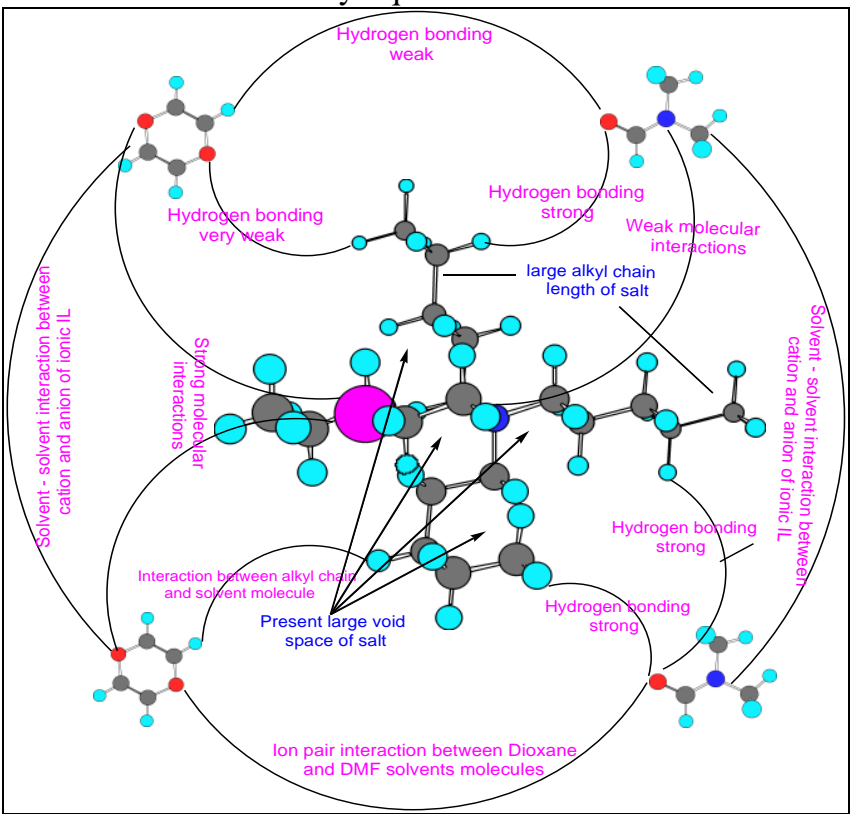


Colours: blue $=$ nitrogen, cyan $=$ hydrogen, black $=$ carbon, red $=$ oxygen and pink $=$ iodide Scheme 3: Penetration of 1,4- Dioxane (chair form) within the large void space of alkyl chain length and planar form of Dioxane as well as N, N - Dimethyl Formamide (DMF) present away from the alkyl chain length.

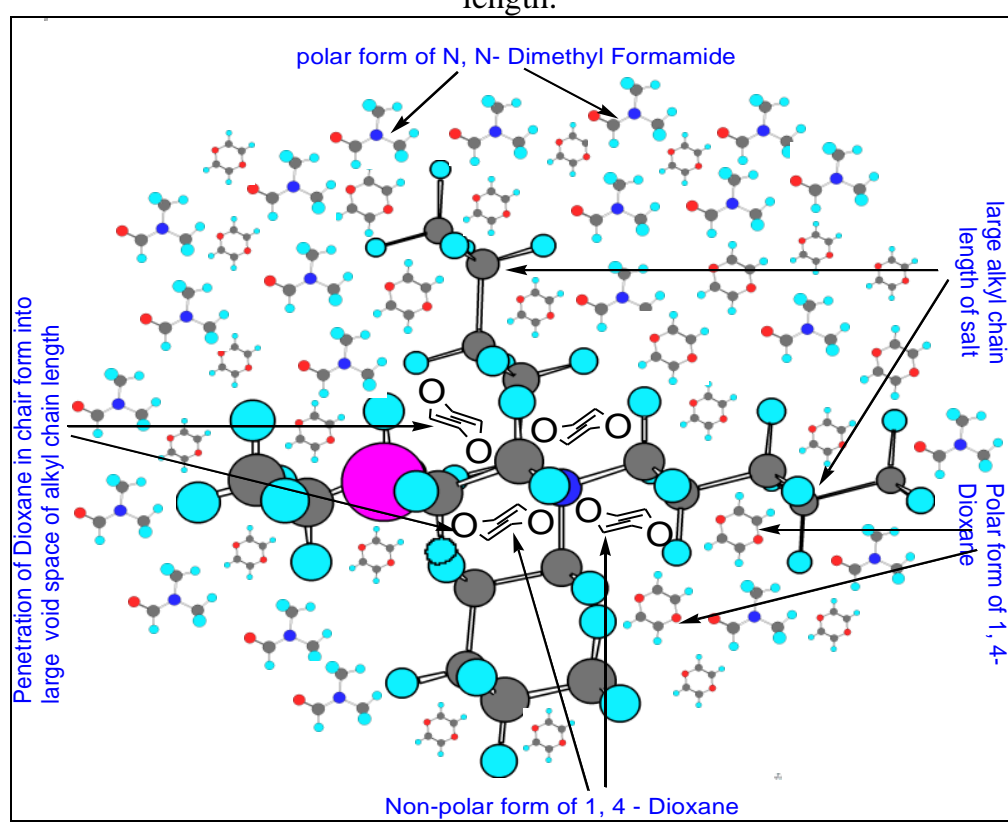

Colours: blue $=$ nitrogen, cyan $=$ hydrogen, black $=$ carbon, red $=$ oxygen and pink $=$ iodide

\section{Acknowledgements}

The author thanks to the Head of the Chemistry Department, Lucknow University for providing the research facility in the Department.

\section{Supporting Information}

Dielectric constants of 1,4 - Dioxane and N, N - Dimetyl Formamide and molecular structure of tetraethylammoniun iodide, tetrapropylammoniun iodide, tetrabutylammoniun iodide, tetrapentylammoniun iodide, Dioxane and DMF are available free charge on the internet at http:// pubs.acs.org.

\section{Footnotes}

Molecular interactions; Effect of large bulky group $\left(\mathrm{R}_{4} \mathrm{~N}^{+}\right)$on the molecular structural and thermo-dynamical properties of binary liquid mixtures at different temperatures

\section{References}

[1] F. J. Trujillo, P. Juliano, G. Barbosa-Canovas and K. Knoerzer, Separation of suspension and emulsions via ultrasonic standing waves - A review, Ultrason. Sonochem, 21, 2014, 2151-2164.

[2] K. Rajagopal and S. Chenthilnath, study of molecular interaction in binary liquid mixtures of ethyl acetoacetate with chloroform and dimethyl sulphoxide, using excess acoustic parameters and spectroscopic methods, Ind J Pure Appl Phys. 48, 2010, 326-333.

[3] M. N. Caro, J. L. Trenzado, S. Galván, E. Romano, E. González, R. Alcalde and S. Aparicio, Densities and viscosities of three binary monoglyme + 1-alcohol system from (283.15 to 313.15K), J Chem Eng Data, 2013, 909-914.

[4] M. C. Grande, J. A. Julia, C. R. Barrero and C. M. Marschoff, Sound velocity measurement in water + acetonitrile system at temperature from 293.15 to $323.15 \mathrm{~K}$ and its implications on the thermodynamic data processing. Phys Chem Liquids, 51, 2013, $457-468$.

[5] J. L. Trenzado, E. Romano, L. Segade, M. N. Caro, E. Gonzalez and S. Galvan, Densities and viscosities of four binary diethyl carbonate 1-alcohol system from (288.15 to 313.15K), J Chem Eng Data, 56, 2011, 2841-2848.

[6] C. Wang, H. Li, L. Zhu, and S. Han, Excess molar volume of binary mixtures of dehydrolinaloo+alkanols at 308.15K, Fluid phase equilib., 189, 2001, 129-133.

[7] G. Xu, X. Li, Y. Hu, Y. Wang, G. Fan and M. Zhang, Density and viscosity of the binary mixtures of triethylene glycol mono ethyl ether + water from (293.15)K at atmospheric pressure, J Chem Eng Data, 55, 2010, 2345-2348.

[8] S. S. Yadava and A. Yadav, Ultrsonic behavior of binary liquid mixtures of 1 - bromo propane with cyclohexane and benzene, Ind J Pure Appl Phys, 42, 2004, 338-340.

[9] L. Sarkar and M. N. Roy, Density, viscosity, refractive index and ultrasonic speed of binary mixtures of 1, 3- dioxolane with 2methoxyethanol, 2-ethoxyethanol, 2- propylamine, J Chem Eng Data. 54, 2009, 3307-3312. 340.

[10] M. N. Roy, R. S. Sah and P. Pradhan, Density, viscosity, sound speed, refractive indices and excess properties of binary mixtures of isoamyl alcohol with some alkoxy ethanol, Int. J. Thermophys, 31, 2010, 316-326.

[11] N. V. Plechkova and K. R. Seddon, Application of ionic liquids in the chemical industry, Chem. Soc. Rev. 37, 2008, 123-150.

[12] P. Attri and P. Venkatesu, thermodynamic characterization of the biocompatible ionic liquid effects on protein model compounds and their functional groups, Phys. Chem. Chem. Phys. 13, 2011, 6566- 6575. 
[13] P. Attri, P. M. Reddy and P. Venkatesu, Density and ultrasonic sound speed measurements for N, N-dimethylformamide with ionic liquids, Indian J. Chem. A, 49, 2010, 736-742.

[14] P. Attri, P. M. Reddy, P. Venkatesu, A. Kumar and T. Hofman, Measurements and molecular interactions for N, Ndimethylformamide with ionic liquid mixed solvents, J. Phys. Chem. B, 114, 2010, 6126-6133.

[15] P. Attri, P. Venkatesu, and T. Hofman, Temperature dependence measurements and structural characterization of trimethyl ammonium ionic liquid with a highly polar solvent, J. Phys. Chem. B, 115, 2011, 10086-10097.

[16] Gallego-Juarez, High power ultrasound processing: recent developments and prospective advances, J. A. Phys. Procedia, 3, 2010, $35-47$.

[17] Zade, and S. D. Rasayan, Study of molecular interactions of coumaran-3-ones in polar and non polar solvent using ultrasonic interferometer, J. Chem. 4, 2011, 620-629.

[18] H. S. Frank, single ion activities and ion solvent interaction in dilute aqueous solution, J Phys Chem., 67, $1963,1554$.

[19] R. N. Pathak, I. Saxena, Archna, R. Kumar and N. Singh, Study of the influence of alkyl chain cation - solvent interactions on the slope $\varphi \mathrm{v}$ vs $\sqrt{\mathrm{C}}$ curves in 1,5 - pentane diol -DMF solvent mixtures by apparent molar volume measurements, Trans Faraday Soc., 3, 2014, 87-92.

[20] R. N. Pathak, I. Saxena, Archna and A. K. Mishra, Study of the influence of alkyl chain cation - solvent interactions on $\mathrm{H}_{2} \mathrm{O}$ structure in 1, 3 - butanediol - $\mathrm{H}_{2} \mathrm{O}$ mixtures by apparent molar volume data, Indian Council Chem., 26, 2009, 2, 170.

[21] H. Eyringand and J. F. Kincaid, Free volumes and free angle ratio of molecules in liquids, J Chem. Phys, 6, $1938,620-627$.

[22] R. N. Pathak, I. Saxena, Magnetic float densitometer- A modified version, Indian J Eng Mat Sci., 5, 1998, $278-284$.

[23] P. S. Nikam, N. Nikam, Hasan and A. R. Hiray, Ultrasonic, volumetric and viscometric studies of monochloroacetic acid $-\mathrm{H}_{2} \mathrm{O}-$ isopropanol solvent mixtures at 30 and $35^{\circ} \mathrm{C}$, Asian Journal of Chemistry, 7(3) 1995, 500-505.

[24] C. Chiappe, C. S. Pomelli and S. Rajamani, Influence of structure variations in cationic and anionic moieties on the polarities of ionic liquids, J. Phys. Chem. B, 115, 2011, 9653-9661.

[25] V. E. Bower and R. A. Robinson, Osmotic and activity coefficient of tetraethyl ammonium iodide in aqueous solution at $25^{\circ} \mathrm{C}$, Trans Faraday Soc., 50, 1963, 1717-1719; DOI:10.1039/TF9635901717.

[26] B. E. Conway, R. E. Verrall and J. E. Desnoyers, Partial molar volume of tetra alkyl ammonium halide and assignment of individual ionic contributions, Trans Faraday Soc., 62, 1966, 2738-2749; DOI: 10.1039/TF9666202738.

[27] T. S. Banipal and G. Sehgal, Partial molal adiabatic compressibilities of transfer of some amino acids and peptides from $\mathrm{H}_{2} \mathrm{O}$ to aqueous sodium chloride and aqueous glucose solutions, Thermochimica Acta, 262, 1995, 175-183.

[28] V. K. Syal, V. Bhalla and S. Chauhan, Ultrasonic studies of some tetra alkyl ammonium salts in acetonitrile + dioxane mixtures at $35^{\circ} \mathrm{C}$, Acustica, 81, 1995, 276.

[29] V. K. Syal, Uma Kumari, S. Chauhan and M. S. Chauhan, Ultrasonic studies of alkali-bromide in dimethyl sulphoxide + dioxane solvent mixtures at $25^{\circ} \mathrm{C}$, Ind. J. Pure and Appl. Phys, 30, 1992, 719.

[30] S. Kalyanasundaram, A. Manuel Stephan, and A. Gopalan, Ultrasonic studies of poly (methyl acrylate) in dimethyl formamide, $J$. Polym. Mater., 12, 1995, 177, 323.

[31] C. R. Read, J. M. Prausnitz, and B. E. Polling, The properties of gases and liwuids, Mc Graw Hill, New York, 1998.

[32] N. Kumar, B. Vijaya, A. R. Sadasiva and K. R. Chowdoji, Ultrasonic velocity study of some glycols and polyglycols in formamide solutions, Journal of Acoustical Society of India, 28, 2000, 297-300.

[33] G. K. Johri and R. C. Mishra, Ultrasonic velocity measurements on tert-butyl alcohol and its phase transition study, Acoustica, 57, 1985, 292-297. 